\title{
Chitosan-based conventional and Pickering emulsions with
}

\author{
long-term stability
}

Supporting Information

Xiao-Yan Wang, Marie-Claude Heuzey*

Department of Chemical Engineering, CREPEC, Polytechnique Montréal, PO Box

6079, Station Centre-Ville, Montréal, QC, Canada, H3C 3A7

*Corresponding author. Email: marie-claude.heuzey@polymtl.ca. Telephone: +1

(514) 340-4711 ext. 5930. Fax: +1 (514) 340-4159. 


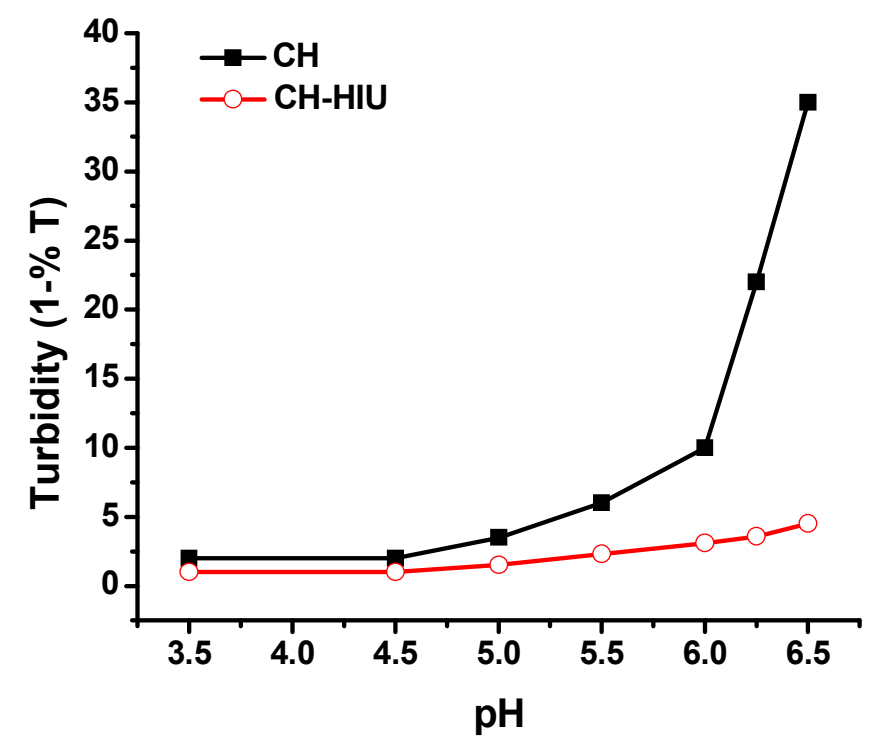

Figure S1. Turbidity profile of chitosan solutions (1 wt \%) with and without HIU

treatment and as a function of $\mathrm{pH}$. 


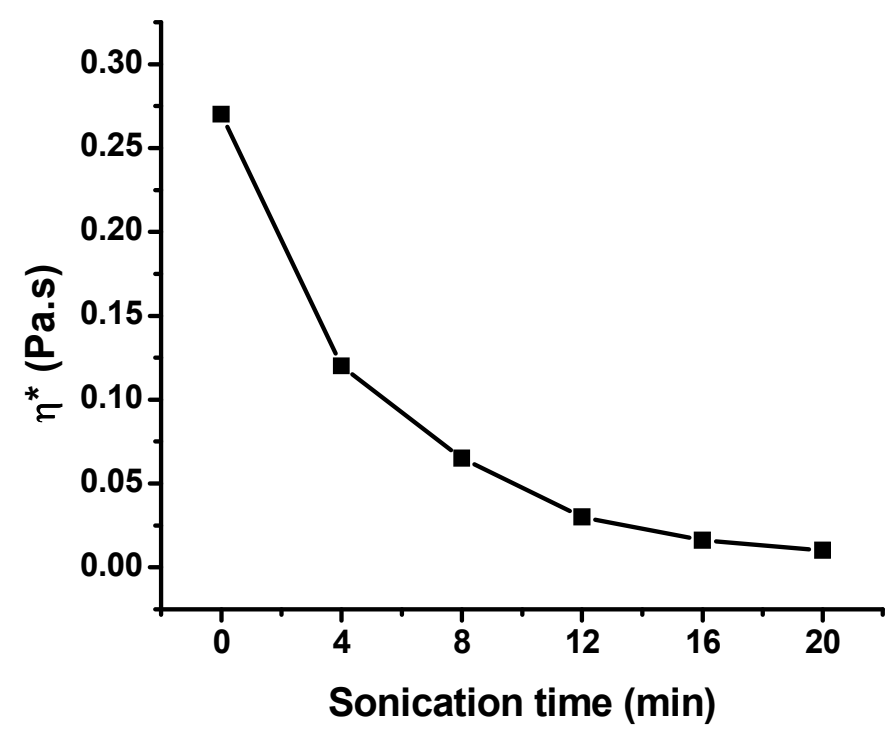

Figure S2. The effect of sonication time on the complex viscosity (1 rad/s) of a chitosan solution (DDA, $85 \%$; dynamic viscosity, 60 mPa.s; concentration, 2 wt \%,

pH 3.9). 


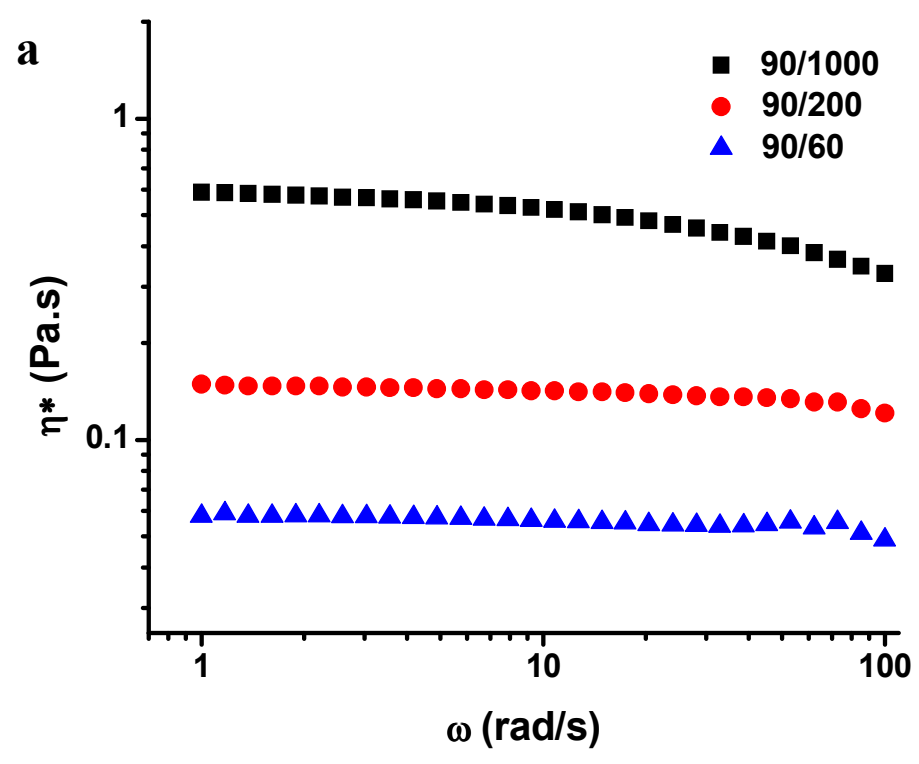

b

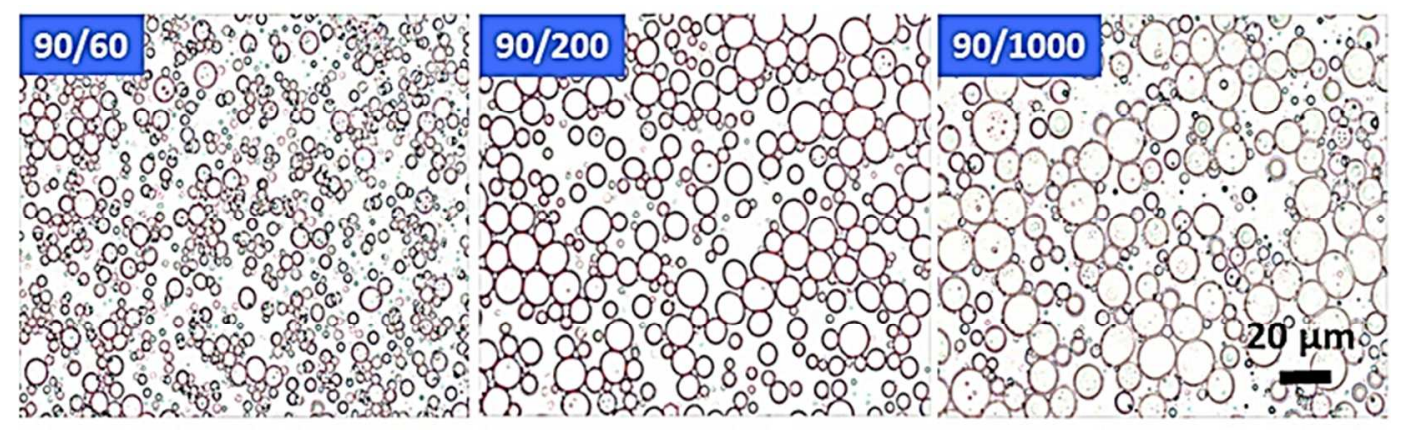

Figure S3. (a) Complex viscosity of chitosan solutions (1 wt \%) at $\mathrm{pH} 4$ for samples

with same DDA (90 \%) but different molecular weights (dynamic viscosity varies

from 60 to $1000 \mathrm{mPa} . \mathrm{s}$ ). (b) Optical microscopy images of chitosan-based emulsions

after $1 \mathrm{~h}$ of preparation, at an oil volume fraction of 0.2 . 